\title{
UM ENCONTRO POSSÍVEL - JEAN LUC NANCY E MAURICE BLANCHOT EM TORNO DA COMUNIDADE SEM COMUNIDADE.
}

\begin{abstract}
Alberto AMARAL ${ }^{1}$
Resumo

Pensar em Maurice Blanchot e Jean Luc Nancy, e lançar-se ao impossível, ao improrrogável, à comunidade que de certa forma, arrisca-se em uma longa incoerência. Uma vez que esses pensadores através de seus textos nos apresentam como é possível pensar a questão da política através da literatura e através disso nos apresentar como a noção de comunidade desenvolvidas por eles, fortemente inspirada no pensamento de comunidade de Georges Bataille nos lança para questionamento dos dias atuais. $\mathrm{O}$ ensaio busca debater um assunto que se faz bastante presente nas reflexões desses pensadores, de suma importância para o pensamento contemporâneo pensar na política - uma política não partidária mais sim um fazer político ético do pensamento um fazer político pelo pensamento literário, que está diretamente ligado ao conceito de comunidade.
\end{abstract}

Palavras chaves: Comunidade; Partilha; Literatura; Política.

\begin{abstract}
Thinking of Maurice Blanchot and Jean Luc Nancy, and throwing themselves at the impossible, the nonextendable, the community that in a way, risked a long incoherence. Once these thinkers through their texts present us how it is possible to think the question of politics through literature and through this to present us as the notion of community developed by them, strongly inspired by the thought of community of Georges Bataille launches us to question the current days. The essay seeks to discuss a subject that is very present in the reflections of these thinkers, it is of the utmost importance for contemporary thinking to think of politics - a nonpartisan politics but an ethical political doing of thought. a political doing by literary thinking, which is directly linked to the concept of community.
\end{abstract}

Keywords: Community; Sharing; Literature; Policy.

\section{Résumé}

En pensant à Maurice Blanchot et à Jean Luc Nancy, et en se jetant sur l'impossible, le non-extensible, la communauté qui risquait en quelque sorte une longue incohérence. Une fois que ces penseurs à travers leurs textes nous présentent comment il est possible de penser la question de la politique à travers la littérature et de nous présenter comme la notion de communauté développée par eux, fortement inspirée par la pensée de la communauté de Georges Bataille. jours. L'essai cherche à discuter d'un sujet très présent dans les réflexions de ces penseurs, il est de la plus haute importance pour la pensée contemporaine de penser à la politique - une politique non partisane mais une pensée politique éthique. une action politique par la pensée littéraire, directement liée au concept de communauté.

Mots-clés: Communauté; Partage; Littérature; Polítique.

\footnotetext{
1 Pesquisador dos grupos de pesquisas Arte, Corpo e Conhecimento (UFPA/CNPq) e Pensamento Blanchotianos e de Pensamento do Fora (UNB/CNPq). Curador e Crítico de arte independente, dedica seus estudos no campo da Filosofia da diferença francesa e sua relação com a Psicanálise. Tendo como seu principal objeto de pesquisa a escrita/escritura da arte improrrogável na historiografia da arte paraense dos anos 70,80 e 90. Tendo como seu principal referencial teórico (Jacques Rancière, Jacques Lacan, Michel Foucault, Gilles Deleuze, Georges Bataille, Maurice Blanchot, Georges Didi-Huberman e Jacques Derrida). Tendo publicações no âmbito nacional e internacional. E-mail: albertoamaral@gmail.com
} 


\section{A COMUNIDADE DE BLANCHOT - UMA QUESTÃO}

Em La communauté inavouable Blanchot nada promete de seu livro além de uma breve reflexão "concernente à falha de linguagem que tais palavras como comunismo ou comunidade parecem conter, se pressentirmos que carregam algo completamente outro que o que poderia ser comum àqueles que pertenceriam a um todo, a um conselho, um coletivo, mesmo quando negam pertencer a ele, qualquer seja a forma em que neguem"².

Sair do livro com respostas do que é uma comunidade, seus processos e a que propriamente se refere essa palavra quando se a menciona está fora do campo de previsibilidade do que é proposto pela obra. O que Blanchot realmente nos proporciona é algo como uma experiência da pergunta. "Comunidade está fora da inteligibilidade", começa-se já nos tirando de vista o que quer que pudesse ser um objeto de pesquisa concernente ao pensamento especulativo ou científico, que acostumou-se a responder suas perguntas. Eis aí os inícios de uma comunidade negativa, mais tarde no livro tratada pormenorizadamente; a comunidade, por não pertencer ao campo da inteligibilidade, não é demonstrável ou de fato cognoscível, seus "defeitos de linguagem" apenas nos "parecem [...] se pressentirmos".

Os conceitos que estão ao redor da "comunidade", do "comunismo", talvez se refiram ao mesmo, apenas em diferentes níveis. Como previsto em Nancy, eles estão além da ruína histórica, são defeituosos por causa de seu abandono. Blanchot ainda insiste em chamar essas palavras de conceitos, das quais observa, "aparentemente", um defeito de linguagem e, senão por causa da terrível ruína e dos restos de fracasso que deixaram a nós historicamente, algo ainda resiste neles de um abandono tout court.

Se Nancy declara ser Rousseau o primeiro pensador da comunidade, em La communauté inavouable, Blanchot fundamenta-se em Morin - "comunismo" como possibilidade de uma outra sociedade, outra humanidade - e diz:

O comunismo, ao dizer que a equidade é seu fundamento e que não pode haver comunidade até que as necessidades de todo homem sejam igualmente

\footnotetext{
${ }^{2}$ Blanchot, Maurice. La communauté inavouable. Paris: Les Éditions de Minuit, 1983, p. 9-10. Tradução do autor.
} 
Alberto AMARAL

preenchidas (isso é em si senão um requerimento mínimo), pressupõe não uma sociedade perfeita, mas o princípio de uma humanidade transparente essencialmente produzida por si mesma, uma humanidade "imanente" (diz Jean-Luc Nancy). Essa imanência do homem ao homem também aponta ao homem como o ser absolutamente imanente pois ele é ou tem que se tornar esse homem tal que ele possa inteiramente ser uma obra, sua obra, e, no fim, a obra de tudo. (Blanchot, 1983, p. 11).

"Aí está a aparentemente saudável origem do mais doente totalitarismo", conclui. Colocando-se enquanto fundamento do comunismo um certo humanismo de fundo, tem-se um comunismo definido classicamente, quer queira também a comunidade definida da mesma forma: enquanto atualização a si de um trabalho de que é o resultado final e ao mesmo tempo o impulso. A comunidade é sob essa ótica o "trabalho" de si mesma, o homem enquanto obra de sua propriedade agrupa-se num desejo de "obra" que é sua própria essência, atualizada numa essência comunitária.

A humanidade transparente é uma comunidade transparente de si à sua obra, que é extensão de seus indivíduos, pois é a essência comum produzida comunitariamente. "Ser inteiramente sua obra": eis aí a sua imanência. Na medida em que é presença pura de si para si, essa comunidade não pode ser feita senão de indivíduos. Isso porque o "trabalho", a "produção", ou mesmo o "sentido" que atualizam, a si e para todos o mesmo, só pode ser referido ou reportado à parte de que se estendem. O "trabalho" é inalienável do indivíduo, e é isso que invariavelmente o torna um sujeito.

O indivíduo afirma-se com seus direitos inalienáveis, sua recusa de ter qualquer origem senão ele mesmo, sua indiferença a qualquer dependência teorética em relação a outro que não seria um indivíduo como ele, isto é, em relação a ele mesmo perpetuamente repetido, seja no passado ou no futuro portanto tanto mortal e imortal: mortal em sua inabilidade em perpetuar a si mesmo sem alienar-se; imortal por que sua individualidade é a imanência de vida que não tem limite em si mesma. (Blanchot, 1983, p. 11 - 12)

A raiz mais extrema da comunidade definida enquanto "obra" de um agrupamento de indivíduos cuja humanidade é repetidamente asseverada enquanto "trabalho final", no entanto sempre em processo, é reconhecidamente o indivíduo. Trata-se aqui de uma relação primordial entre o entendimento social e político de uma comunidade enquanto seguimento lógico do indivíduo, o átomo indivisível que, 
matematicamente, se soma a outros átomos, formando um simples agrupamento de agregados cujas partes são privadas de outras partes (a-tomo).

Deixe-se ressaltar que a observação da comunidade enquanto fenômeno social, político ou mesmo "intersubjetivo" é notadamente a primeira a resistir uma fenomenalização pelo justo axioma de sua pertença a algo outro que não ao campo da inteligibilidade. Essa resistência à fenomenalização de fundo metodológico caminha junto de uma resistência da parte dos indivíduos - que compõem uma certa comunidade suspensivamente factual - de proporem sua própria individualidade, "a imanência de vida", enquanto limite de si mesma em cada individualidade conformadora.

É certo que há duas "comunidades" em La communauté inavouable. Uma é como que a explicitação do que se tem enquanto ranço de um comunismo fracassado e de certo humanismo. Outra é a tentativa de entendimento do que teria querido Georges Bataille com suas obras ficcionais, quando se deixa espantar pelas concepções de "comunidade", "experiência interior", "êxtase", "comunicação", "erotismo" etc. Quanto à segunda, aí vemos que a literatura, os textos narrativos de Bataille, é responsável por responder às perguntas feitas apenas posteriormente pelo pensamento teórico.

Bataille teria sugerido uma comunidade, que não se deixa pensar fora de uma comunidade literária ou comunidade entre leitores e escritor. Em princípio, somente Nancy aponta para uma comunidade escritural, permanecendo fiel aos textos literários de Bataille. Em La communauté desoeuvrée, ele menciona que a comunidade não se dá senão por uma inscrição. A concepção de escritura de Jacques Derrida é "toda e qualquer inscrição" que seja e Jean-Luc Nancy compartilha do léxico derridiano. A inscrição, que não se atém somente à letra, põe em jogo sentidos em devir através da différance e funciona como alternativa à concepção estruturalista de "literatura". Quando Nancy põe a inscrição em um imperativo a priori para a comunidade, o que temos é que, segundo Nancy, a comunidade é primeiramente escritural.

Contudo, mesmo a comunidade a que Blanchot se aproxima via Bataille não está ainda indeterminada de "obra". Isso porque ela ainda resiste em uma individuação qual seja. 


\title{
2. O PRINCÍPIO DE INSUFICIÊNCIA
}

O indivíduo cuja "individualidade é a imanência de vida que não tem limite em si mesma" é por isso imortal; e também, pois, mortal "em sua inabilidade em perpetuar a si mesmo sem alienar-se". Estão aí em jogo dois movimentos similares. A mortalidade é justificada pela inabilidade em continuar sem alienação; perpetuar-se sem sair de si, sem exceder-se em um outro ou perder consciência plena de seu "trabalho" ou daquilo em que participa na feitura de comunidade, na comunidade.

A imortalidade, por sua vez, é a "imanência de vida" que encontra seu limite além de si. Mais uma vez, o indivíduo, que terá no "sujeito" sua autossuficiência e liberdade privativa, é predicado em sua essência, a individualidade, enquanto excesso e perda do que o define mais propriamente, seus limites indivisíveis, sua finição, para a externalidade impredicada.

\begin{abstract}
"Existe um princípio de insuficiência na raiz de cada ente..." (o princípio de incompletude). Deixe-nos tomar nota que o que comanda e organiza a possibilidade de um ente é um princípio. Segue-se que essa falta em princípio não caminha junto com uma necessidade de completude. Um ente, insuficiente tal como é, não tenta associar-se com outro ente para formar uma substância de integralidade. A consciência da insuficiência vem do fato de que se coloca em questão, questão essa que necessita o outro ou um outro para ser encenada (Blanchot, 1983, p. 15)
\end{abstract}

Se o indivíduo tem seus limites, confins e términos, há que se permitir que também tenha um princípio. Nos dois sentidos que pode tomar essa palavra, o princípio que começa e o princípio que rege, o indivíduo é aqui tomado enquanto ente. $\mathrm{O}$ princípio de insuficiência radical dos entes não os fundamenta enquanto faltantes de uma soma posterior. Numa dialética pressuposta, seria sem surpresa dizer que algo que é de nascimento incompleto espera sua completude de algo outro, posteriormente.

No entanto, é assegurado que o princípio de incompletude não se serve para uma justificativa ou entendimento da comunidade enquanto preenchimento de faltas pelos outros que formam suas partes. A comunidade não é, segue-se disso, uma integralidade, uma "substância de integralidade" cujo agrupamento de insuficiências as completaria num indivíduo (a unidade íntegra) per se. Pela questão da comunidade, ela mesma 
sendo uma insuficiência de partes predicadas como "indivisíveis", é que se percebe o "princípio de insuficiência" na raiz do ente, ao fundo do indivíduo também. Este último, no entanto, continua indivisível em sua falta incompletável, isto é, apesar de qualquer falta, insuficiência, essas não se abrem à um preenchimento, a uma completação.

O que se vê aí de fundo, e o que queremos propor fundamentalmente é que o esgarçamento do indivíduo, sua insuficiência e suas faltas não passam de princípios régios de fundamentação de sua "readaptada" integralidade. "Um ente, insuficiente tal como é, não tenta associar-se com outro ente para formar uma substância de integralidade" (Blanchot, 1983, p. 15)

A comunidade, começa-se a perceber, não significa "juntar" os sozinhos para fazê-los acompanhados em relação à obra que os qualifica enquanto comunidade. Blanchot nos mostra que só é comunidade se e porque a "obra" que organiza e assimila seus partícipes é justamente a mesma que os une e invariavelmente os separa na partilha de uma solidão.

A figura da separação em um pensamento da comunidade é importante na medida em que essa define a relação entre comunidade e indivíduos - no sentido que assume essa palavra enquanto base para um pensamento sobre "entes", que acontece em termos de uma individuação progressiva e em estratos, de cima a baixo, numa conformação situacional. O indivíduo é radicalmente separado de tudo que lhe é outro.

A questão do indivíduo e da comunidade - e a aparente relação sem laços que aí se dá, uma relação não relativa pois não fundamentada no princípio de uma dependência nem de uma privação, como é questionado por Jean-Luc Nancy nas figuras de liberdade e suficiência - dizem ambas respeito à imanência enquanto questão geral.

Uma comunidade não funcionaria de todo contrariamente à imanência de que predica sua "obra" humana, logo, não seria a imanência de que propriamente a comunidade é questão uma transcendência programada e inatual quando o caso é uma comunidade inoperante? De fato, a passividade que assombra Blanchot não toma proporções de não-produção de essência na comunidade inoperante de que fala, pelo contrário, essa passividade, de que não se fala explicitamente mas sobredomina a obra, 
pode ser entendida de outra maneira: a partir dela a comunidade inoperante se torna produtora de inessência, inoperância enquanto produção de ausência.

Nesse sentido, a comunidade inoperante blanchotiana não é não operante, produtora de nada ou nenhuma obra. Ela não é indeterminada ou desapropriada. Ela ainda tem propriedade e determinação. Isto é dizer que ela ainda implica uma ontologia. Ela opera e produz in-essência. Isso porque para Blanchot a obra não é feitura de um resultado final e atual, fático. A obra opera desde um centro de ausência, mas ainda desde um centro. Ela é impossibilidade de atualização, de completar-se. Mas essa é sua essência. Suas produções e operâncias são predicadas a partir de figuras de inessência. Assim o "branco", o "vazio", o "silêncio", a "noite".

Por isso a comunidade blanchotiana também advém de um gesto literário. Ela tem sua fonte no pensamento figurativo. É desdobrada por metáforas, imagens, elementos plásticos que engendram um pensamento argumentativo.

Pode-se predicar a ausência enquanto "obra" de uma qualquer comunidade sem que deslinde a "obra" por uma noite comunitária cuja escuridão é partilhada em indivíduos invisíveis de seus limites? Isso seria o esperado. No entanto, o que acontece em La communauté inavouable está longe de uma partilha de ausência entre deslimites.

Os participantes da "comunidade inconfessável" são ainda indivíduos, entes que estão bem demarcados em suas individuações e limites. O que acontece é a incomunicabilidade de uma experiência faticamente partilhada entre indivíduos. Isso é dizer que La communauté inavouable, portanto, passa pela questão da imanência; o que é questionado é a comunicabilidade da experiência, é a inessencialidade da produção de sentido entre os entes, a partilha enquanto distribuição de ausência entre indivíduos.

O que não é questionado, no entanto, em La communauté inavouable é:

1) O limite enquanto pressuposto necessário para a experiência (experienciação) e a comunicabilidade à qual também está intricada, na medida em que a comunicabilidade é pressuposto da experiência (e vice-versa) - Bataille proporciona pensar na incomunicabilidade da experiência a partir do êxtase, que é necessariamente uma nãoexperiência devido à saída de cena do conceito de limite, que inexiste numa abertura para a exterioridade que equivale o dentro ao fora como o é no êxtase; 
2) A alteridade enquanto aporia do limite; se a comunicabilidade pressupõe a alteridade, em que o limite afeta a alteridade no caso de uma incomunicabilidade por ausência de limites ao indivíduo, que propriamente desfaz-se no êxtase? Isto é: como pode o limite ser pressuposto da experiência (e, por tabela, da comunicabilidade que pressupõe a experiência e vice-versa) ao mesmo tempo em que a experiência pressupõe e necessita a alteridade (assim como a comunicabilidade)?

Essa questão se complexifica quando se leva em conta o incômodo que causa a Blanchot o pensamento de uma comunidade ainda afastada de "obra". Certo que essa é uma concepção blanchotiana, mas talvez Nancy a tenha compreendido melhor em seu La commuanuté desoeuvrée, em que a distinção entre indivíduo e alteridade é feita claramente. Em Nancy há talvez uma resistência à noção de indivíduo, de membros de uma comunidade, pois ele questiona a própria noção de limite, de limites, portanto, que constituem uma individuação.

Nancy nos lembra que a comunidade inoperante só pode ser constituída de singularidades. A noção de singularidade é semelhante à de alteridade, à qual não cabe divisibilidade. Que a comunidade seja, no trabalho de Blanchot, constituída de indivíduos, faz necessário, cabal mesmo, que os indivíduos tivessem produções a seu alcance, extensões de si mesmos e entendimentos de- si que constituíssem a produtividade de sua essência comunitária. Esse é o próprio pressuposto de indivíduo. Sua indivisibilidade vem com um direito a suas extensões, um entendimento de si pelo seu trabalho, portanto implica em "obra".

O fato é que Blanchot parece estar ainda arraigado em uma noção individuada de comunidade. Está claro que seu entendimento de "comunidade" insiste em uma "supraindividualidade".

\section{COMUNIDADE E INDIVIDUAÇÃO}

Não é incomum que a singularidade enquanto conceito resvale-se às figuras da alteridade numa coextensividade conceitual que é ao mesmo tempo figurativa. Nancy entende singularidade e alteridade como indiferentes. Na passagem de Blanchot acima, 
Alberto AMARAL

no entanto, "pensamentos que podem ser apenas pensados juntos" se agrupam ao redor de uma catraca e a multiplicidade que os torna propriamente múltiplos impede que passem e completem a ação para que se juntaram ali.

É aceito que uma catraca tem seu design pensado junto à unidade que é seu propósito de uso e justificativa de uma certa morfologia funcional. Não é certo que a força que "reside na mistura de diferenças associadas", esse "entrelaçamento de motivos dissimilares" cuja força ainda resiste uma análise, impediria-os à quebra perpetrada por uma qualquer divisão de suas partes, mantendo-os impensavelmente unidos, mas ainda sim resistentes também à pluridade?

A imagem de uma catraca não acabaria, portanto, por positivar uma certa unidade ao "pensamento"? É certo, todavia, que esses pensamentos não conseguem passar pela catraca, mas, em vez de não conseguirem por não constituírem unidade, não conseguem porque são muitos. A "multiplicidade mesma" é que dificulta a passagem ${ }^{3}$. O conceito de unidade é ainda regulador em Blanchot pois que, p. ex., "multiplicidade" do pensamento não pode senão referir-se a uma série finita e, portanto, numerável e definível.

Ou mesmo: um pensamento que necessitaria de uma coletividade, ou ao menos de uma não individualidade, poderia ser sequer pensado ${ }^{4}$ ? Não acabaria ele por predicar

\footnotetext{
${ }^{3}$ Reporto aqui à ressalva que faz Derrida quanto a seu "conceito" de différance. Este último diferencia-se por completo de uma polissemia, pois que a polissemia é constituída de partes unitárias derivadas de um significado preferido e anteposto às outras possibilidades de significação, que podem ser estabelecidas em seu número e relação ao significado comum e dicionarizado; é certo que tais possibilidades podem inclusive se constituir como desvios, sentidos figurados, regionais etc. Já a différance é predicada somente metafórica e figurativamente. Ela é uma "tessitura" cujo trabalho não se pode parar, ela é um devir de significação que, no entanto, não pode ser predicado como tal. Seu processo é impossível que seja parado pois suas limitações são o horizonte de possibilidades da "obra", que se mantém entre finição e infinito. Portanto, para a polissemia, há uma regulação da parte de um conceito de unidade que mantém os significados numeráveis (porque tornados signos) e estabelecíveis. Para, contudo, a différance, não há conceito regulador de unidade e essa é de fato sua singularidade. Para um aprofundamento da questão da différance e da disseminação e suas relações com escritura, traço e rastro: La dissémination, Seuil, 1972; Marges de la philosophie, Ed. Minuit, 1972. Para trechos dialogados sobre esse tema: Positions, Ed. Minuit, 1972. Para a especificidade da différance, em Van Gogh e nas artes "plásticas" de modo geral, La vérité em peinture, Flammarion, 1978.

${ }^{4}$ É certo que a questão do pensamento e sua diferença à escritura está na seara de Artaud. Em termos analíticos, pode ser dito que em $O$ pesa nervos ele se questiona se é possível pensar um pensamento pelo suporte escritural. A figura de um abismo que se coloca entre o pensamento e sua expressão "estética", em desenho ou em palavras (ambos para Derrida constituem inscrição e, portanto escritura), é o que conta no questionamento de Artaud, que terá, talvez, alguma resposta em Nancy e sua figura de limite intocável, com o jogo etimologizante entre pensée e pesée.
} 
o múltiplo à individualidade e unidade à alteridade mesma? A multiplicidade dos pensamentos pensados juntos ainda não é o princípio de comunicabilidade que os rege desde a alteridade que é o pressuposto da comunicação. Contrariamente, o pensamento será em Nancy um conceito cujo pressuposto é a alteridade (com valor de singularidade) que resiste à comunicabilidade e que necessita de uma concepção única de espacialidade ${ }^{5}$.

Incontáveis são os esquemas que pretendem programar dentro à sistematicidade do pensamento demonstrativo algumas relações de fraternidade eidética entre os temas aqui expostos.

Com o que se segue, pretende-se demonstrar o funcionamento da ideia de Aufhebung e como ela implica em uma metafísica. De fato, ela é um processo de manutenção metafísica. Isso significa dizer que ela opera e faz manejo ao serviço de uma lógica do Mesmo. Pretende-se com isso aproximar o apego de Blanchot à individualidade como uma permanência no logocentrismo da ipseidade, isto é, um reestabelecimento da violência do Mesmo. Para isso, analisa-se a "supraindividualidade" de que Blanchot predica a comunidade inconfessável como uma figura de sobrelevação (Aufhebung) e melhoramento da individualidade.

A comunidade em Nancy é uma abertura. Ela é também um entendimento ontológico, seu assunto é, enfim, o ser-comunitário; no entanto, ela propõe um pensamento ontológico da singularidade, e não do indivíduo.

O "espírito" hegeliano é uma individualidade coletiva - um "Eu" que é um "Nós" ou mesmo o contrário - e não um conjunto de individualidades. Ele questiona a própria questão de uma multiplicidade unitária e uma unidade que pode ser múltipla, revendo em estado de dúvida tanto sujeito quanto sociedade.

A "comunidade inconfessável" de Blanchot sem dúvida não é tão facilmente explicada como um "conjunto de individualidades" e certo está que declará-la símile do "espírito" hegeliano talvez necessite um melhor explicitamento do que quer que "espírito" tenha significado mesmo para Hegel, o que permanece, sem dúvida, a ser

\footnotetext{
${ }^{5}$ Para essa questão: Le toucher - Jean-Luc Nancy, Ed. Galillé, 2000. 
Alberto AMARAL

feito. Contudo, percebe-se ainda em Blanchot a permanência de uma unidade atrás das figuras de multiplicidade.

É necessário no entanto esclarecer que o Absoluto e o "espírito" a que é por vezes equivalente, em Hegel, não constituem o mais geral do pensamento dialético. $\mathrm{O}$ "espírito" é, e não é, o resultado final de um processo. Por tratar-se de uma dialética transcendental, o último estágio de pensamento é também o mais "puro" e mais "originário". Isso o torna produto metodológico de um pensamento cujo resultado é o começo mais originário e possibilidade de qualquer pensamento que seja. Tendo em vista o "didatismo" dos estados sugeridos por Hegel como mais próprios de um sistema que desse conta de todo outro sistema, o fim que é o começo, se torna um tanto mais claro. As etapas que constantemente rejeita e profere falhas são substituídas por outras e outras até que se esteja satisfeito com um tipo de sistema.

A batalha das consciências, um dos estados sugeridos por Hegel, pode ser explicada primeiramente no que tem de batalha além do nome. Figura-se uma situação tal que uma consciência - que num primeiro momento resiste o nome de "sujeito" encontra-se consciente de um objeto de que é consciente. Toda consciência requer uma transitividade desse tipo. O objeto de que é consciente por sua vez também é uma consciência. Ambos são autoconscientes e lutam para posicionarem-se numa hierarquia entre senhor e servo. Essa é uma das interpretações da cena.

Há uma outra, em outro nível. Como cada uma das consciências é autoconsciente, trava-se internamente uma outra batalha ao nível "psicológico": toda consciência é ciente de alguma coisa. Nesse caso, o caso da autoconsciência, há que se estabelecer, se se quiser manter o léxico "sujeito", "objeto", "consciência" e os esquemas que dele se segue, um sujeito e um objeto. Para uma autoconsciência que é ciente de si mesma, ela é ao mesmo tempo sujeito e objeto; primeiramente, no entanto, cria-se duas consciências, mas uma deve morrer e tornar-se objeto da outra. 


\section{O AMOR E O DESEJO, AUFHEBUNG}

Uma certa análise da cena da "batalha das consciências" não deve apressar-se em tratá-la enquanto faticidade de batalha ou como dados fáticos de uma consciência qualquer; trata-se, muito provavelmente, de uma cena, isto é, uma dramatização didática, adicione-se. O seguinte trecho de La communauté inavouable lembra uma das etapas a serem superadas (aufheben) no caminho dialético empreendido por Hegel, a "batalha das consciências", que, ao mesmo tempo, é a figura da própria superação, denegação, sublevação, rélève (Aufhebung) por que se deve guiar.

Um ente não quer ser reconhecido, quer ser contestado: para existir vai em direção ao outro, que o contesta e por vezes o nega, para então começar a ser apenas naquela privação que o torna ciente (aqui jaz a origem da sua consciência) da impossibilidade de ente em si, de subsistência enquanto seu ipse ou, quer queira, como ele mesmo enquanto indivíduo separado. (Blanchot, 1983, p. 16)

A descrição acima de um "indivíduo" separado encaixa-se perfeitamente à "batalha" hegeliana de consciências. O trecho "um ente não quer ser reconhecido, quer ser contestado" chama atenção pelo uso do verbo querer. Trata-se, portanto não de um dever, mas de um desejo ${ }^{6}$.

Tomemos o trecho em Blanchot do ente que "para existir vai em direção ao outro, que o contesta e por vezes o nega, para então começar a ser apenas naquela privação que o torna ciente". Ora, para Hegel é aí que jaz a origem da consciência e que toma, em Kojève, o estatuto de um "desejo de preenchimento" que acontece através ou apesar de uma denegação pela privação. A consciência aflora-se apenas na total independência de objetos do consciente, que não passaria de um objeto também por ser

\footnotetext{
${ }^{6}$ Alexandre Kojève já reconhecidamente tratou da figura do desejo e de sua importância em Hegel, principalmente na cena das consciências. Kojève foi importante figura na introdução de Hegel à França no sec. XX e a importantes pensadores contemporâneos franceses. Georges Bataille, entre eles, atendia a seus seminários sobre Hegel na École Pratique des Hautes Études de Paris durante os anos 33-39 que trataram da leitura de Fenomenologia do espírito. O pensamento de Bataille é estudado em Blanchot e Nancy com o estatuto de epígrafe. É inclusive notória a "influência" de Kojève nos trabalhos "literários" de Bataille como por exemplo a História do olho em que o "desejo de preenchimento" de que trata Kojève conceitualmente em Introdução a Fenomenologia do espírito é como que reconfigurado em plasticidade estética e narrativa na obsessão pelo personagem batailliano a quem assombram as imagens de branco e vazio.
} 
essa a propriedade qualitativa de objeto. Já para Kojève, a dominação do objeto pela consciência que o hierarquiza inferiormente é somente compreensível pelas imagens eróticas de "preenchimento do vazio" e "desejo."

Teria Bataille figurado em seus textos o erotismo de que para uma "fenomenologia da consciência" kojèviana é o princípio? Com o acima exposto, quer-se novamente ressaltar a importância da literatura na medida em que é a partir dela que surgem as questões. Mesmo se se diz que Bataille teria figurado Kojève, a questão complexifica-se e em muito ultrapassa o pensamento teórico pois basea-se na figuração e na imagem, portanto abertura de sentido, e não definição de fechamento.

\begin{abstract}
Uma comunidade é historicamente de poucos números e aponta para uma efeverscência juntando os elementos apenas para dar nascimento a uma unidade (uma supraindividualidade) que se exporia às mesmas objeções vindo da simples consideração do indivíduo único, fechado em sua imanência. (Blanchot, 1983, p. 17)
\end{abstract}

Aqui Blanchot prepara uma transição da comunidade pensada enquanto agrupamento para uma comunidade entre dois, o casal ou os pares. É interessante notar que há alguns tons de hegelianismo ainda presentes. No trecho "dar nascimento a uma unidade (uma supraindividualidade)", pode-se relacionar ao "espírito" a supraindividualidade nascida da efervescência. ${ }^{7}$ A comunidade blanchotiana é invariavelmente afastada de sua própria imanência pelo movimento de uma "sobrelevação" a uma unidade que se autosuprimiria em sua possibilidade de presença. O que a comunidade inconfessável partilha de comum entre seus indivíduos é de fato "fala, silêncio". Retornamos à questão de uma comunidade que distribui ausências para confirmar que a comunidade é ainda definível a partir de uma divisão entre seus indivíduos, e que há individuações de certo pelos entes que a constituem. A partilha no entanto fica como que inefetuada ou inefetuável pelo fato de que aquilo que é partilhado ser "incorpóreo" ou inindividuável.

\footnotetext{
${ }^{7}$ São palavras de Blanchot que ecoam uma certa Aufhebung da comunidade: "Donc, [...] la communauté n'a pas à s'extasier, ni à dissoudre les éléments qui la composent en une unité surélevée qui se supprimerait elle-même, en même temps qu'elle s'annulerait comme communauté" (Op. cit., p. 19).
} 


\section{COMUNIDADE E INSCRIÇÃO, PARA ESCRITURAS.}

O que então chama-me à questão o mais radicalmente? Não minha relação a mim mesmo como finito ou a consciência de ser-ante-a-morte ou para-amorte, mas minha presença para o outro que se ausenta morrendo. Permanecer presente na proximidade de outro que por morrer remove-se definitivamente, tomar para mim mesmo a morte do outro como a única morte que me concerne, é o que me põe à parte de mim mesmo, é a única separação que me pode abrir, em sua impossibilidade mesma, à Abertura de uma comunidade. (Blanchot, 1983, p. 17)

"O que [...] chama-me à questão o mais radicalmente" é certamente um momento do texto em que Blanchot propõe a morte como uma figura de alteridade que, no entanto, não é ainda Outro, senão outro, pois é o que chama o Mesmo à questão "mais radicalmente". Para Heidegger a Abertura $^{8}$ é, finalmente, o que põe o Dasein em questão, portanto serve ao Mesmo. Heidegger, portanto, nos mostra que a propriedade última do Dasein, o que mais o concerne e também o que o acorda para um entendimento-a-si radical, é justamente o chamado à questão que o tira de sua queda; a radicalidade e as palavras do léxico da "raiz", fundamento, "fundo" e "base" apenas ressaltam uma pertença do tema, às voltas em Blanchot e Nancy, ao pensador alemão.

Também é nesse trecho acima que se vê primeiramente a aparição da palavra "abertura", que, junto a "clareira" e outras imagens como "ponte", p. ex., formam a rede de sentido que na obra heideggeriana é operante conceitualmente e faz um trabalho semântico de fundo, passando-se incógnita como jargão técnico 9 .

\footnotetext{
${ }^{8}$ Uma das leituras prevalentes para a "abertura" heideggeriana é que consiste em uma figura de alteridade. Enquanto abertura ao outro. No entanto, a abertura em Heidegger é o que mais chama o Dasein à questão de si mesmo. Atualiza-o frente ao mundo (Nancy nos lembra que "o indivíduo é um mundo", e que, portanto, o mundo é individuação). A abertura, por isso, serve ao Ser, ao Mesmo, o ipse. Ela não abre portanto à alteridade, mas altera o Mesmo em outro mesmo.

${ }^{9}$ Blanchot aqui ecoa um certo Heidegger. O "ser-com", cujo "ser-no-mundo" só se dá presentemente à atualização-a-si (e adiantamento de uma possibilidade ausente) de um entendimento-de-ser frente à morte, o que, com Blanchot, toma nova importância de revisão do projeto heideggeriano paralelo ao conceito de comunidade. Em Heidegger também o ser-finito é originariamente determinado pelo ser-com seu modo de ser mais originário e geral. A importância do "ser-com", e consequentemente do projeto heideggeriano, para a questão da comunidade é difícil de explicar sem uma análise que se detivesse majoritariamente nessa questão. Por hora as palavras de Nancy são suficientes: "A comunidade não cria laços de uma vida imortal, transmortal ou mais além entre sujeitos [...] É constitutivamente [...] ligada à morte daqueles que se chamam, talvez erroneamente, seus membros" (1990, p. 41). Talvez mais claramente ainda seria dizer que a comunidade é anterior ao indivíduo. A comunidade é figura mais geral do "ser-comunitário"/sercom-unitário que se acentua mais expressivamente na morte enquanto propriedade partilhada entre os
} 
O que mais radicalmente "chama-me à questão" é "minha presença para o outro que se ausenta morrendo". Eis o problema da imanência, que é propriamente a questão para a comunidade. Em "permanecer presente na proximidade de outro que por morrer remove-se definitivamente", tem-se a questão da comunidade levada à inscrição do luto, que tanto pela substituição ou pelo abismo entre a necessidade lógica de uma substituição e sua atualidade impossível pela singularidade da perda, fazem para-acomunidade uma inscrição de sentido em que "sentido" é o último sentido enquanto chegada, o ponto de basta que organiza tudo. Ainda não se vê, contudo, e talvez só se o veja em Derrida, a morte como figura de alteridade que não é numa atualidade, e sim, num porvir messiânico em que não há atualização da vinda.

A inscrição da morte enquanto inscrição comunitária em discrições ou segmentos de intervalos vitais para os viventes torna o outro, sempre o outro, "o único a possibilitar [...] ao menos a súplica à fala que carrega consigo o risco de rejeição ou perda ou não recebimento". É desde o dom da fala enquanto advindo de e indo ao outro ou o outro enquanto doador da morte, pois que o dom e morte se inscrevem pela alteridade, que pressente-se que "[...] a comunidade, em seu próprio fracasso, está ligada com uma certa forma de escrita, uma escrita que não tem nada a mais para procurar senão as últimas palavras"

No entanto, já se havia dito que a comunidade não tem trabalho e que não se une num trabalho que é a atualização de seu sentido-a-si ou consciência de valor ou propósito. Como então conceber uma total ausência de obra e produção ao entendimento da comunidade como uma substância originária como um paralelo com Heidegger o faria ser necessário? A substancia originária em uma ausência não conformaria no entanto ainda uma obra? Novamente com Blanchot é dito, talvez um tanto peremptoriamente nesse formato de citação, que "Cada membro da comunidade [...] é [...] a [...]encarnação impotente da totalidade de entes que, tendendo a existir integralmente, têm como corolário o nada em que já [...] caíram" (Blanchot, p.28.1983). O que suprimiu-se do trecho citado foram apenas algumas muito importantes locuções

seres e organizadora de suas vidas em medidas de sentido realizáveis em individuações ou conformadoras de individuação desde que findem. 
adverbiais que tornavam a frase mais cuidadosa e tentativamente afirmativa, ao passo que no formato citado tem-se quase um axioma definitivo.

O que se quer reter do trecho, e talvez aí algum traço de peremptoriedade seja requerido, se não desejado, é que o "cada" em cada membro é o instante ou estância de singularidade que impotentemente encarnada como a "totalidade de entes que [...] têm como corolário o nada em que já, e antes da hora, caíram", é valida enquanto individuação de uma totalidade de indivíduos numa impossibilidade ordenada que apenas a mais quadrada lógica de conjuntos invejaria em suas formas mais oblongas. Não resistimos a uma reformulação do trecho e completamente entregamo-nos aqui ao risco possibilíssimo de embaçar com a citacionalidade descuidada as frases limpas de Blanchot e intencionalidade perigando máculas.

Outrora "antes da hora", unindo-se a um "já" de antecedência, cada um de seus membros que individua a totalidade do agrupamento todo "tem como corolário o nada em que caíram". Eis que o "nada" é predicado enquanto corolário, consequência e, ao mesmo tempo "já" e "antes da hora" o transforma em princípio e pressuposto. Há interessantemente uma predicação "substancial" no nada em que caíram as instâncias de totalidade referente ao todo.

Nancy abre seu livro La communauté desoeuvrée, uma resposta que começa o diálogo, de todo modo ela e qualquer outra resposta vem antes da pergunta, ao dizer que vai tratar do "testemunho mais importante e mais penoso do mundo moderno, aquele que une talvez todos os outros testemunhos que essa época se encontra encarrega de assumir"; talvez dois Testemunhos: "nós testemunhamos também o esgotamento do pensamento da História". Mas de todo modo, é do "testemunho da dissolução, do deslocamento ou da conflagração da comunidade" de que trata o texto.

Os deslocamentos sociais, tecnopolíticos, culturais, compreendendo estéticos, psicológicos, cognitivos, e por fim, teóricos já ao nível da textualidade, perpassam a abrangência da palavra numa familiaridade herdada o tronco aos galhos etimológicos, lexicais, especializados dos aspectos semânticos da palavra. É aí que se vê a especialidade linguística ou de linguagem que toma o problema da comunidade. Nancy, 
por exemplo, tem como capítulo de abertura de seu La communauté desavouée, um texto que trata da comunidade e o nome.

[A] palavra "comunismo" serve como emblema do desejo de descobrir ou redescobrir um lugar de comunidade a uma só vez além das divisões sociais e além da subordinação ao domínio tecnopolítico, e por isso além de tal gasto de liberdade, de discurso, ou de simples felicidade que advém sempre que esses ficam subjugados à ordem exclusiva da privatização (Nancy, 1991, p. 01)

Se tal desejo de descoberta é antes político ou antropológico, é por isso que que é admitida a possibilidade no texto presentemente inclassificável de Nancy de redescobrir um lugar de comunidade. Mas talvez essa tentativa de redescoberta seja um novo descobrimento, deslocado ou, de todo modo, traidor daquele que o precede - não é preciso uma traição para o estabelecimento de uma tradição? Senão traição de algo futuramente enquanto ideia, então daquilo enquanto ideia futura de um passado contínuo, tradicional, herdado.

A felicidade que "advém sempre que esses [gastos] ficam subjugados à ordem exclusiva da privatização" remete à comunidade em seu estado mais amplo e de modo geral não redutível ao casal, ao par. Se a privatização não é referida a uma situação dual, entre dois, é por que ela se refere ao objeto mesmo da política, uma partilha ou distribuição do espaço disponível e a consequente interdição e controle estatal desses espaços, para que, assim, seja compreensível uma ocupação deles, da parte de quem compete ocupa-los.

Uma certa tipologia e valorização dos espaços não prescinde da preocupação objetiva da política: distribuição de poder, sua discussão metafísica, em espaços materiais e sensíveis, as únicas propriedades, ou mesmo qualidades objetais, recebedoras de valor econômico e sociocultural. Se Jacques Rancière já houvera introduzido e já também exaurido de belíssimo modo essa questão em seu Le partage du sensible: Esthetique et politique, é justamente por isso que permanece a discussão de uma tecnopolítica em Nancy como uma redescoberta, admitida senão alternativamente. Quanto ao comunismo enquanto fracasso:

[Isso] não é apenas porque os Estado que aclamaram por ele [comunismo], apareceram, por algum tempo já, como os agentes de sua traição. O esquema 
Alberto AMARAL

da traição, com o objetivo de preservar uma pureza comunista originária de doutrina ou intenção, tem sido vista como cada vez menos sustentável. Não que o totalitarismo tenha já estado presente, como tal, em Marx: isso seria uma proposição rude, uma que permanece ignorante do protesto exaltado contra a destruição da comunidade que em Marx compara-se à tentativa hegeliana de trazer à tona uma totalidade, e que frustra ou desloca essa tentativa (NANCY, 1991, p. 2)

A questão de uma sustentabilidade do comunismo enquanto projeto tem a ver com sua difícil atualização e implementação. Tudo tem a ver com um necessário abismo entre ideia e mundo. Talvez o "comunismo", "comunidade" e "comunhão", junto a eles toda a discussão de espaços comuns e exclusivos, sejam a figura mais emblemática dessa separação, que dá a ver, ao nível mundano, diferenças morfológicas, ontológicas e axiológicas, portanto, na separação dos indivíduos. Vai aqui sem muito retoque um paralelo, por alto, com a descontinuidade socioeconômica entre indivíduos de que fala Rancière em La nuit des proletaires. Essa disparidade, ou descontinuidade, reflete-se numa outra relação com o tempo dos indivíduos que vivem de restos da elite, não com a temporalidade, mas com a organização do tempo diário, cotidiano.

Em termos, também uma divisão temporal e espacial do trabalho que implica numa disponibilidade de seus corpos e numa regulação outra de sua fisiologia e força de trabalho. Isso se estende à discussão de valor de trabalho já que essa descontinuidade entre indivíduos é de todo uma separação segundo o valor da presença e estar-nomundo. Nesse sentido, uma tal diferença ontológica é sempre uma descontinuidade de valor.

\section{COMUNISMO: IDEÁRIO FRACASSADO DA PARTILHA}

Quanto à traição do ideário comunista, está longe de ser uma traição de suas ideias. A implementação do comunismo depende de uma ideia de totalidade perdida. A perda dessa totalidade imaginada, pensada nostalgicamente por algum artifício cognitivo, é de algum modo posta em objetivação quando implementa-se uma nova sociedade, novos termos de vivência entre os viventes. O "assombro" da ideia do comunismo é que historicamente sempre se tornou em totalitarianismo. 
Foi a própria base do ideal comunista que acabou-se por parecer mais problemática: nomeadamente, seres humanos definidos como produtores (pode-se até adicionar a isso: seres humanos definidos de qualquer modo), e fundamentalmente enquanto produtores de sua própria essência na forma de seu trabalho ou sua obra. (NANCY, 1991, p. 3)

Definir seres humanos "de qualquer modo" é já dar a eles uma finalidade. O comunismo enquanto uma espécie de humanismo desloca a essência do homem a uma essência produzida "na forma de seu trabalho ou sua obra". É por isso que pelas bases de um comunismo enquanto regime político tem-se o "[...] propósito de atingir uma comunidade de seres produzindo em essência sua própria essência como sua obra, e ademais produzindo precisamente essa essência enquanto comunidade" (Nancy. p 2.1991). A essência produzida não se distingue da totalidade presumida. Deixar que o homem produza sua essência por sua produção é diminuir a descontinuidade entre os Indivíduos. A comunidade pensada e idealizada pelo comunismo, essa que "desafastaria" as distâncias entre o seres ao dá-los um ponto comum é "uma de seres humanos [que] pressupõe que efetua, ou que deve efetuar, enquanto tal e integralmente, sua própria essência, que é em si o cumprimento da essência de humanidade" (NANCY, p.3.1991)

Consequentemente, laços econômicos, operações tecnológicas e fusões políticas (em um corpo ou sob um líder) representam, ou melhor, apresentam, expõem e realizam sua essência necessariamente em si mesmas. A essência está em obra nelas; através delas, torna-se sua própria obra. Isso é o que chamamos "totalitarianismo", mas pode ser melhor nomeado "imanentismo", desde que não restrinjamos o termo para designar só certos tipos de sociedades ou regimes, mas sim Ver nele o horizonte geral do nosso tempo, abarcando tanto as democracias e seus frágeis parapeitos jurídicos. (NANCY, 1991, p. 3)

É nesse sentido que a comunidade apresenta a si um corpo único. Ao aproximar de si seu trabalho, ou ao unificar os trabalhos de suas partes produzindo o mesmo resultado, a essência do que os une, a comunidade torna-se um outro indivíduo, um só corpo cuja totalidade é cada uma de suas partes pela soma de suas qualidades, idênticas. O comunismo é um problema Indenitário. O "totalitarianismo", que pode ser um "imanentismo", é a presunção, primeiramente teórica, de que a essência do homem está 
nele mesmo, não independe dele, nem o transcende, não é inalcançável, nem está longe do alcance do que suas mãos produzem.

No entanto e apesar de o individualismo não ser a primeiridade, a comunidade, desde aí, seria um mero agrupamento, Nancy apregoa que "a experiência pela qual esse indivíduo passou, desde Hegel pelo menos, [...] é simplesmente a experiência do seguinte: o indivíduo pode ser a origem e a certeza de nada senão de sua própria morte" (p. 3). Isso significa que comunidade, pelo fenômeno do "comunismo" indicaria uma resiliência de recuperar-se em um só corpo apesar de tantos choques a sua "sustentabilidade" e essência baseia-se justamente no fato de que sua substância é sua produção ou resultado, a imanência é o que está em jogo aí.

A comunidade como uma dita figura da imanência permite a pergunta do que é o indivíduo então, sob essa lente. Para Nancy, a individualidade é "uma outra, e simétrica, figura da imanência: o absolutamente desligado por si mesmo, tomado como origem e certeza" (NANCY, p.3.1991). Por isso, o indivíduo seria uma outra forma de absolutismo e totalidade. Para Jean-Luc Nancy, há quem veja na invenção e na cultura do individualismo, "senão no culto construído ao redor do indivíduo, o mérito irrefutável da Europa de ter mostrado ao mundo o único caminho de emancipação da tirania" ((NANCY, p.3.1991). Seria o indivíduo um mero deslocamento necessário da comunidade de um "comunismo" falho? Uma troca de imanência e absolutismo que historicamente ainda resistiam o aniquilamento?

O indivíduo, historicamente, é a ele reservado um nascimento desde a Antiguidade. Para alguns, a lírica foi esse nascimento. Desde que se começou a falar "eu". Para outros, o direito romano é a prova viva, com o surgimento da comunidade privada, de uma recém descoberta individualidade. É de Marx a crítica de que o indivíduo não pode ser anterior à comunidade, senão uma abstração do conceito de uma comunidade. Nancy o repete ao considerar que o indivíduo é nada senão "o resíduo da experiência de dissolução da comunidade. Por sua natureza [...] o átomo, o indivisível [...] o indivíduo revela que é o resultado abstrato de uma decomposição" (NANCY, p.3.1991)). Contudo, em Nancy, o indivíduo é o resultado de uma dissolução da tentativa frustrada de comunidade, ao passo que em Marx ainda havia esperanças de retomada do 
verdadeiro a priori da comunidade numa implementação natural que ia além de uma implementação, a comunidade viria pelo curso natural de um processo histórico que ultrapassava e ao mesmo tempo definia o progresso da humanidade.

De fato, se "o individualismo tende a esquecer que o átomo é um mundo" (NANCY, 1991, p. 4), é pelo fato de a questão da comunidade estar de tal modo "ausente da metafísica do sujeito, quer dizer, da metafísica do absoluto para si mesmo - seja na forma do indivíduo ou do Estado total - que significa também a metafísica do absoluto em geral" (NANCY, 1991, p. 4). Seja Estado ou indivíduo, ambos são figuras de uma requerida totalidade ainda não advinda, a comunidade está ausente de tanto uma quanto a outra. Isso é porque a dita "metafísica do sujeito" (haverá outra?) é uma metafísica da presença e presentificação do absoluto. De uma suficiência da presença e de sua independência (não é certo que Bataille tenha criado uma metafísica do erotismo? Não é subvalorizada sua proximidade com Hegel) a qualquer coisa que se relacione a ela. Para Nancy essa é uma metafísica do "ser como ab-soluto, como perfeitamente desvinculado, distinto e fechado: ser sem relação" que pode aparecer, de fato como se trata de uma metafísica, é necessário que apareça, tanto "na forma da

Ideia, História, o Indivíduo, o Estado, Ciência, a Obra de Arte e por aí vai. Sua lógica será a mesma no tanto em que é sem relação" (NANCY, 199, p. 41)

No entanto, "a lógica do absoluto viola o absoluto. Implica-o numa relação que ele recusa e impede por sua própria essência" (NANCY, 1991, p. 4). O absoluto implica uma lógica que nega o próprio absolutismo que promete. Para ser absoluto, algo deve ser em-si, sem relação com nada. No entanto, o absoluto não pode deixar de se relacionar com ele mesmo, implicando-o numa relação consigo que exclui o fora e a externalidade ao mesmo tempo que nega a própria ideia de uma separação ou absolução, pois que relaciona-se em-si, consigo e para-si, uma ideia de solidão. Contudo, "a relação (a comunidade) é, se é que é, nada senão o que desfaz, em seu princípio mesmo - e em seu fechamento ou em seu limite - a autarquia da imanência absoluta" (NANCY, 1991, p. 4). Talvez por isso a tentação de afastar continuamente a comunidade de qualquer ontologia possível. Afastá-la de todo de uma metafísica da presença ao propô-la 
somente enquanto promessa. A comunidade, excluída da metafísica do absoluto, desfaz a ab-solução do absoluto.

O que Nancy quer propor com uma revisitação à comunidade é que, talvez, o "Ser ele mesmo [venha] a ser definido como relacional, como não absoluto [...] é o que em todo caso tento argumentar [...] como comunidade" (NANCY, 1991, p. 6). Em verdade, uma tal revisitação do tema da comunidade em Nancy é também um resgate reapropriativo de Heidegger. O que Nancy propõe, no entanto, é um ser-comunitário a partir da singularidade e não da individualidade.

\section{HERANÇAS E RELEITURAS DA COMUNIDADE}

Contudo e apesar, talvez mesmo seja o caso de um "apesar", Heidegger em Ser $e$ Tempo, de 1923, já havia ressaltado a importância de que o Ser fosse entendido em modos-de-ser e que aquilo que o definiria de modo mais largo e portanto mais originário - também diferenciava ontológico de pré-ontológico -, aquilo que primeiramente definia o ser ontologicamente era o modo de ser-com. Isso vinha consonante com um projeto de reanalisar a importância da metafísica ocidental que, para Heidegger, havia esquecido propriamente o Ser, cuidando sempre, e ao invés, do ente. Isso para Heidegger é resolvido com um melhor entendimento de diferença ontológica, que é justamente saber reconhecer o que é pré-ontológico e o que pertence à seara da ontologia, com a distinção entre ente e Ser.

Não há, claro, como desatrelar o ser-com de uma relação intensa e originária com a morte. Nem desligá-lo de seus outros modos-de-ser, contudo menos originários porque derivados do ser-com. Outrora reduzido a mero ente, Heidegger pretende que o Ser, para ele, jamais discutido antes de seu livro, seja propriamente um ser-com. É somente nesse modo-de-se que pode-se falar em apresentação ou configuração de mundo para o Dasein em Heidegger. O ser-com de Heidegger não é comunitário. Ele é ainda o individualismo do consigo e a imaculabilidade do Dasein a quem a espacialidade ainda assombra.

O projeto heideggeriano foi acolhido com um esperança de um ideário de um ser-relacional. Nesse sentido, a proposição de um ser-"comunitário" por Jean-Luc 
Nancy é justamente a retomada de um ser relacional, e não absoluto como no fim das contas propõe Heidegger com a negação do ôntico pelo ontológico. Negar uma imanência não é necessariamente querer dizer uma transcendência. É apenas legar ao ser uma requerida ou necessária relação, que também não confunde-se com uma dependência.

O êxtase [...] estritamente falando, define a impossibilidade, tanto ontológica quanto gnosiológica, da imanência absoluta (ou antes do absoluto e, portanto, da imanência) e consequentemente da impossibilidade seja de uma individualidade, no sentido preciso do termo, ou de uma pura totalidade coletiva. O tema do indivíduo e o do comunismo estão intimamente ligados à (e juntamente ligados na) problemática geral da imanência. Estão ligados em sua negação do êxtase. (NANCY, 1991, p. 6)

O êxtase como conceituado por Bataille serve para Nancy como contraexemplo da individualidade ou bem mesmo de uma imanência que é o pressuposto de uma subjetividade qualquer e de qualquer experiência que seja, cujo pressuposto é a subjetividade imanente. Como no êxtase há somente abertura e "transcendência", não há ali possibilidade de um sujeito que o experiencie, não há ali nem mesmo experiência possível. Novamente, com Jean-Luc Nancy:

[C]omunidade não é apenas comunicação íntima entre seus membros mas também sua comunhão orgânica com sua própria essência. É constituída não somente por uma justa distribuição de bens e tarefas, ou por um equilíbrio feliz de forças e autoridades: é feita principalmente da partilha, difusão ou impregnação de uma identidade por uma pluralidade em que cada membro identifica-se apenas através da mediação suplementar de sua identificação com o corpo vivo da comunidade. No lema da República, fraternidade designa comunidade: o modelo da família e do amor. (NANCY, 1991, p. 9)

Nesse sentido, para a comunidade, cujas partes comunicam-se pela partilha do que lhes há de comum, essas partes tem em comum justamente a comunidade que lhes une. Em resumo, para Nancy, há também que: "em sua história o Ocidente deixou-se cair em nostalgia por uma comunidade mais arcaica que desapareceu, e [deixou-se] deplorar uma perda da familiaridade, fraternidade e convivência" (NANCY, 1991, p. 10) De maneira similar à "conceituação" do amor por Marguerite Duras em seu récit, em Nancy, "[o] que essa comunidade "perdeu" - a imanência e a intimidade de uma 
comunhão - está perdido apenas no sentido em que tal "perda" é constitutiva da própria "comunidade" (NANCY, 1991, p. 12)

Há, contudo ainda a necessidade de clarificar o pertencimento da morte à questão da comunidade. Por isso: "A pessoa plenamente realizada de humanismo comunista ou individualista é a pessoa morta"; continua-se que, "Em outras palavras, morte, em tal comunidade, não é o indomável excesso de finitude, mas o cumprimento infinito de uma vida imanente: é a própria morte consignada à imanência" (NANCY, 1991, 13)

O motif da revelação, do ser-junto ou ser-com, e da cristalização da comunidade em volta da morte de seus membros, isto é em volta da "perda" (a impossibilidade) de sua imanência e não em volta de sua assunção fusional em uma hipóstase coletiva, leva a um espaço de pensamento incomensurável à problemática da socialidade ou intersubjetividade (incluindo a problemática husserliana do alter ego) dentro da qual a Filosofia apesar de seus esforços permaneceu cativa. A morte irremediavelmente excede os recursos de uma metafísica do sujeito. (NANCY, 1991, p. 1)

A "perda" é uma representação passadista de uma impossibilidade atual e futura da imanência e, portanto, presença e existência de comunidade. É por isso que o lugar da comunidade é o de assumir a "impossibilidade de sua própria imanência [...], de um ser comunitário na forma de sujeito. Num certo sentido a comunidade reconhece e inscreve - esse é seu gesto singular - a impossibilidade de comunidade" (NANCY, 1991, p. 15). No entanto, a perda é também a "morte de seus membros" em torno da qual a "civilização da comunidade" se revela e cristaliza-se; nesse sentido não há representação possível da morte, ou mesmo é pela morte que se vê a impossibilidade mesma de qualquer representação.

Em dado momento de La communauté desouvrée, Nancy sente-se responsabilizado de ter de mencionar a grande sombra que permeia sua revisitação de Heidegger pela ótica da comunidade e política.

Fascismo ignóbil, e fascismo enquanto um dos recursos do capitalismo, esse fascismo abominável foi também uma tentativa de responder - abominável e ignóbil - ao já estabelecido, já sufocante reinado da sociedade. O fascismo foi o grotesco ou abjeto ressurgimento de uma obsessão com a comunhão; ele cristalizou o motivo de sua suposta perda e a nostalgia por suas imagens de fusão (NANCY, 1991, p. 17). 
Fascismo é um estabelecimento falseadamente transcendentalizado de um comunismo que não se pauta no porvir, mas tenta colocar em imanência (como qualquer comunismo, em verdade, fora da teoria) uma ideia de comunidade com mais apego à produção de sujeitos de uma comunidade que se vê em trabalho; tenta por em imanência algo que se revela apenas enquanto impossibilidade de imanência e, portanto, ausência. O fascismo revela a relação inextrincável do comunismo com a individualidade e soberania.

Ao se colocar contra tudo o que "está aí", o estabelecido, ao se pautar num discurso da mudança, uma nova sociedade, e ao mesmo tempo emblematizar a família e continuidade reprodutiva como os símbolos do que já havia sido a fraternidade humanista, o fascismo aproxima-se de um entendimento de comunidade fundamentado numa ideia comunitária de transcendência regressiva, ou, ao menos um momento suspensivo de transcendência para uma "nova imanência", um novo "aí" que a um só gesto conserva e supera.

O comunismo é testemunho da congregação e comunhão enquanto esperanças de estabelecimento enquanto vontade de estabelecimento e instauração de uma nova ordem, nesse sentido ele é o estabelecimento como o assentamento da poeira e ao mesmo tempo a faxina do dia depois. Por mais bobo que possa parecer, é justamente a faxina a imagem mais adequada às obsessões comunitárias do fascismo. Ela é a mudança do "estabelecido", limpeza da poeira, e também a volta do que está "perdido" nos estados atuais, renovação, nostalgia e conservação.

O outro para a comunidade é apenas uma derivação especular ou projeção redutora, uma representação objetiva de um sujeito "para representação subjetiva". Deve-se conceituar, e primeiro diferenciar, indivíduo singularidade e alteridade. Dessa forma, a individuação é um processo que "desapega entidades fechadas em si de um chão sem forma - enquanto que apenas a comunicação, o contágio ou a comunhão constituem o ser dos indivíduos" (NANCY, 1991, p. 17). Enquanto que o indivíduo é uma decantação da comunidade, uma abstração de seu fracasso e uma decomposição de sua impossibilidade, para Nancy, a singularidade é de todo o contrário. 
A singularidade talvez não proceda de nada. Não é uma obra resultante de uma operação. Não há processo de "singularização", e a singularidade é nem extraída, produzida ou derivada. Seu nascimento não tem lugar de.. ou como um efeito de..: pelo contrário, ele provê a medida de acordo com a qual o nascimento, como tal, é nem uma produção nem um autoposicionamento, a medida segundo a qual o nascimento infinito da finitude não é um processo que emerge de um chão [fond] ou de um fundo [fonds] de algum tipo. (NANCY, 1991, p. 27)

Tendo em vista que a individuação desapega do chão "entidades fechadas em si", comparada à singularidade, os indivíduos provém, advém, são produzidos. A singularidade não advém nem resulta ou deriva-se de qualquer processo. Nela não há fundo nem chão. Seu nascimento não é nem "produção nem autoposicionamento", como seria com o caso de uma consciência identitária.

Em outras palavras, a comunidade é antes "aquela ordem ontológica singular em que o outro e o mesmo são semelhantes [sont le semblable]: isto é, na partilha da identidade" (p. 34). Nesse sentido, "comunidade" é qualquer mais de um em que há outro e mesmo. A comunidade é a base de uma discussão ética. Nancy nos lembra da incompletude da partilha.

Incompletude é seu "princípio", tomando o termo "incompletude" num sentido ativo, no entanto, designando não insuficiência ou falta, mas a atividade de partilha, o dinâmico, quer queiram, de uma passagem ininterrupta através de rupturas singulares. Isso é dizer, de novo, uma atividade sem trabalho e inoperante. Não é questão de fazer, produzir, ou instituir uma comunidade; nem é uma questão de venerar ou temer um poder sagrado - é questão de in-completar sua partilha. A partilha é sempre incompleta, ou está além da completude e incompletude. Pois uma partilha completa implica um desparecimento do que é partilhado (NANCY, 1991, p. $35)$.

A partilha para Nancy no entanto é a comunicação. A comunidade cujo princípio é incompletude a partir da partilha, é uma comunidade da literatura.

"[L]iteratura" não designa aqui o que essa palavra ordinariamente indica. $\mathrm{O}$ que está de fato envolvido é o seguinte: que há uma inscrição da exposição comunitária, e que essa exposição, enquanto tal, pode apenas ser inscrita, ou pode ser oferecida apenas por meio de uma inscrição. (NANCY, 1991, p. 39)

Isso nos demonstra que a noção de escritura está intimamente ligada à comunidade. Não porque há comunicação em partilha, mas porque a comunidade expõe-se em uma inscrição. A marca inscrita é que designa o pertencimento à comunidade. 


\section{REFERÊNCIAS.}

BATAILLE, Georges. O erotismo. Trad. Antonio Carlos Viana. s/l: L\&PM

Editores, s.d.

OEuvres complètes. Paris: Gallimard, 1987.

BLANCHOT. La communauté inavouable. Paris: Les Éditions de Minuit, 1983.

. L'écriture du desastre. Paris: Gallimard, 1980.

. L'espace litteraire. Paris: Gallimard, 1955.

O livro porvir. SP: Martins Fontes, 2005.

DERRIDA, Jacques. Gramatologia. Trad. Miriam Schneidermann e Roberto

Janini Ribeiro. São Paulo: Perspectiva; Edusp, 1973.

DERRIDA, Jacques. A voz e o fenômeno. Trad. Lucy Magalhães. Rio de

Janeiro, Jorge Zahar Ed., 1994.

. Pensar em não ver. MICHAUD, Ginette; MASÒ, Joana; BASSAS,

Javier (Org.) Trad. Marcelo Jacques de Moraes. Florianópolis: UFSC, 2012.

. De la grammatologie. Paris: Minuit, 1967.

. L'écriture et la différence. Paris: Seuil, 1967.

La voix et le phénomène, Introduction au problème du signe dans la phénoménologie de Husserl. Paris: PUF, 1967.

. Marges de la philosophie. Paris: Minuit, 1972

. Khôra. Paris: Galilée, 1993.

. Passions. Paris: Galilée, 1993

Sauf le nom. Paris: Galilée, 1993

. Spectres de Marx. Paris: Galilée, 1993

HEGEL, G.W.F. Cursos de estética I. Trad. Marco Aurélio Werle. - $2^{\mathrm{a}}$ ed. rev.

São Paulo: Editora da Universidade de São Paulo, 2011.

HEGEL, G.W.F. Fenomenologia do espírito. Trad. Paulo Meneses. Petrópolis:

Vozes, 1992.

HEIDEGGER, MARTIN. Ser e tempo. Trad. Fausto Castilho. São Paulo: Editora

Unicamp; Vozes, 2012.

KOJÈVE, Alexandre. Introdução à leitura de Hegel. Trad. Estela dos Santos

Abreu. RJ: Contraponto: EDUERJ, 2002.

NANCY, Jean Luc. La communauté desoeuvrée. Paris: Christian Bourgeois éditeur, 1999.

. La communauté desavouée. Paris: Éditions Galillé, 2014. 